\title{
Religiosity in relation with psychological distress and mental wellbeing among Muslims
}

Raza, Hassan

University of Sargodha (Mianwali sub-campus), Pakistan (subengineer15@yahoo.com)

Yousaf, Anam $\bowtie$

University of Sargodha (Mianwali sub-campus), Pakistan (anam.yousaf@ymail.com)

Rasheed, Rakshanda

University of Sargodha (Mianwali sub-campus), Pakistan (rakshandarasheed@yahoo.com)

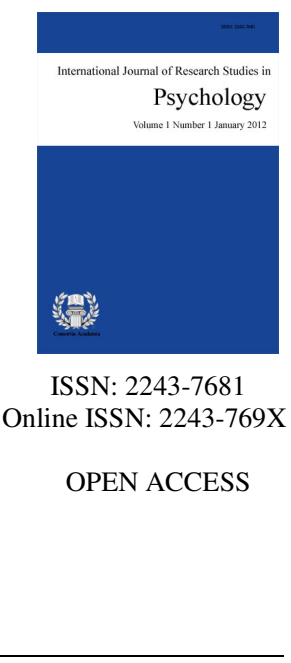

\section{Abstract}

The aim of present research was to investigate the relationship among religiosity, psychological distress and mental wellbeing. The current study was conducted on a purposive sample of undergraduates and graduates taken from University of Sargodha, Mianwali sub-campus and Chashma city $(n=100)$. The sample comprised of male $(n=50)$ and female $(n=50)$. In order to measure religiosity, psychological distress and mental wellbeing, English version of Centrality of Religiosity Scale (Huber \& Huber, 2012), Kessler Psychological Distress Scale (Kessler et al., 2002), and The Warwick-Edinburgh Mental Well-being Scale (Tennant, Hiller, \& Platt, 2007) were used respectively. Linear regression analysis portrayed that religiosity is significant positive predictor of mental wellbeing while religiosity appeared as a non-significant correlate of psychological distress. Data analysis also revealed that mental well-being is significant negative predictor of Psychological distress. Moreover, the analysis revealed that the mean scores for the females significantly higher on religiosity and psychological distress. While non-significant gender differences were found in mental wellbeing.

Keywords: religiosity; psychological distress; mental wellbeing; purposive; predictor 


\section{Religiosity in relation with psychological distress and mental wellbeing among Muslims}

\section{Introduction}

A long time ago, religion has slowly become departure from the practice of Medical field, despite having been stick to it for centuries. From ancient times, through Mesopotamian civilization and Indus Valley civilizations over hundreds and thousands of years ago, continuing on through ancient Greek civilizations and the Roman Empire, until the dark ages and revolutionary movement Renaissance and the periods of glory which is the age of enlightenment, religion was clearly associated with both psychological and physical health and the treatment of psychological problems and illnesses (Koenig, 2000).

Religiosity is a concise term used to refer to the various domains of religious activity, dedication, and belief (religious doctrine). It is defined in terms of both beliefs and religious practices regarding an organized religious affiliation or an authority and divine power (Pargament, 1997; Shafranske \& Malony, 1990). While, psychological distress is largely described as state of emotional turmoil manifested by symptoms of depression (e.g., lost interest; sadness; hopelessness) and anxiety (e.g., restlessness; feeling tense) (Mirowsky \& Ross, 2002). Symptoms are also related to physical symptoms (e.g., insomnia; headaches; lack of energy). Stress distress model explains that psychological distress is construct which manifest itself when person is exposed to distress which have negative effects on health, person is disable to cope with the distress or and the without effective coping person is facing emotional burden (Horwitz, 2007; Ridner, 2004).

Most of the researches have examined that mostly indicators of religiosity are oppositely associated with dimensions of psychological ill-health (Bergin, 1983). Underlying mechanism which is used to explain this relationship is the buffering hypothesis; religiosity may buffer the impact of distress on psychological wellbeing and physiological health (Kendler, Gardner, \& Prescott, 1997; Krause, 1998; Pargament, 1997).

A person's most deeply held beliefs and faith strongly influence his or her health on mental and physical level. Some researchers believe that faith and beliefs increases the body's resistance to psychological distress. Following study investigated the association between religious affiliation and practices, spirituality and quality of life (QoL) and stress in breast cancer patients who are recovering and surviving. The sample included 130 women assessed with 2 years following diagnosis. Results through hierarchical multiple regression analysis found that spiritual well-being was significantly correlated with quality of life and traumatic stress, whereas non-significant relation was found between religious practice with these variables (Efficace \& Marrone, 2002).

Another analysis of approximately 200 studies shows a number of findings. First, a constructive relationship between religiosity and positive functioning regarding psychological wellbeing was revealed in a number of areas (Gartner, Larson, \& Allen, 1991). World Health Organization provide a brief report operationally defining positive mental health as a "state of well-being in which the individual knows his or her own abilities and capacities, copes with the normal stressed of life, works productively, fruitfully with devotion and enthusiasm and makes a contribution of his or her social environment" (WHO, 2001, p. 1).

In the same line, a study examined the association between religiosity and psychological wellbeing among Pakistani Muslims. Previous researchers are in line with current study and they showed positive link between religiosity and mental wellbeing. The sample (65 men and 85 women) with an age range from 18 to 60 years was the sample of study. Consistent with previous research, correlation statistics suggested that a strong, negative association does exist between religiosity and anxiety $(\mathrm{r}=-0.511)$. A strong positive relationship was also found between religiosity and life satisfaction $(r=0.76)$. Thus, the results of this study supported the relationship between religiosity and different dimensions of psychological well-being (Ismail \& Desmukh, 2012).

Moreover Aflakseir (2012) conducted research on Muslims students who are concerned with meaning of life 
and they are trying to find meaning through religion and its relationship with wellbeing of a person. 60 Muslim students studying at University of Southampton and Birmingham in England were selected as participant of the study. The participants were administered following scales; life attitude profile-revised scale, sources of meaning profile-revised scale, psychological well-being scale, and strength of spiritual belief scale. Results of this study showed that there was a positive correlation between different dimensions of personal meaning and different components of psychological well-being, spirituality and religiosity.

Another research by Abdel-khalek (2008) on a sample of 424 Kuwaiti employees (219 men, 205 women; $M$ age $=37.6 \mathrm{yr}$., $S D=8.9 ; M$ age $=33.4 \mathrm{yr}$., $S D=7.9$, respectively), religiosity was found to be the significant and positive correlate of physical health, mental health, and psychological health. Principal components analysis of the correlation matrix produced only one outstanding factor characterized as well-being, health and religiosity which explained $52.7 \%$ and $56.5 \%$ of the variance for men and women, respectively. Similarly, Koenig and Larson (2001) steadily reviewed 850 studies and discover several correlations between religiosity and mental wellbeing in all researches. Of those studies that correlated religiosity with life satisfaction, 80 percent demonstrated a greater life satisfaction is achieved by religious beliefs and practices. Other studies which are demonstrating religion role in depression reported less depression and anxiety in religious people's then non-religious. On over all bases it shows that positive relationship befalls between religiosity and mental health.

On the debate of gender differences in religiosity there are different views among researchers. Some researchers tended to claim that religiousness is higher among females (Stark, 2002). Likewise, Deconchy (1973) in a comprehensive analysis of children's possibilities for conceptual, religious, and relationship tasks, found that girls specific religiousness not an in born quality and not used for identifying characteristics, but that results are dependent upon social constraints in which it is constructed. According to his concluding remarks the idea of women religiousness is based upon ideology, doctrine, dogma and objectively, as it is ostensibly and seemingly prima facie and apparent to some people. Moreover another independent study which was conducted to find gender differences in religiosity demonstrated that after including suitable regulators male have low religiosity level than female. It demonstrated that the differences are not providing real depiction due to sociological issues like prejudices regarding gender roles and these difference between gender are somewhat exaggerated (Cornwall, 1989). Additionally, Feltey and Poloma (1991) suggested that females are stereotypically attributed as more religious and therefore these findings are deceptive in some cases.

On the debate of gender role theory and psychological distress women have higher levels of distress than men because women's roles are more distress related and due to these roles women's are more prone to distress. Role played by women are more helping and encouraging and men's roles are most goal or aim directed (Gove \& Tudor, 1973). Various researches reported that stressful life events contribute to psychological distress and ill health (Kessler, Price, \& Wortman, 1985). In another study of Almeida and Kessler (1998) men's face fewer days with distress than women in daily life. Differential exposure and vulnerability to the stressors leads toward chronic stress in both males and females (McDonough \& Strohschein, 2003). However, lot of significant gender differences also remains if behavioral, structural and psycho-social changes take place. It has also been found that coping resources also play a vital role to deal with chronic stress, but the effects of chronic stress are generally higher in women than men (Denton, Prus, \&Walters, 2004).

Along with these, gender differences in psychological wellbeing as addressed by Abdel-Khalek (2014) regarding a correlation between sex-related differences in religiosity, health and happiness. A sample $(n=239)$ of Lebanese adolescents was enlisted (111 boys and 128 girls). Oxford happiness inventory was used for participant's responses, the satisfaction with life scale, the love of life scale as well as five self-rating scales to assess happiness, satisfaction, mental health, physical health, and religiosity. Boys score higher on the scales than girls participants. All the Pearson correlations between the study scales were significant and positive. Principal components analysis yielded two prominent components in boys and labeled happiness, religiosity and health. In girls, only one component was observed, and labialized as health, religiosity and happiness. It was come to an end with the concluding remark that those consider themselves as enjoying happiness, experienced 
Raza, H., Yousaf, A., \& Rasheed, R.

good mental and psychological wellbeing and more religious.

Despite of all these researches some investigations have also proved that there is no correlation between religiosity and mental wellbeing (Kritchmann \& Strous, 2011; Leondari \& Gialamas, 2009; Rosmarin, Kenneth, Pargament, \& Mahoney, 2008). The contradiction between results of previous findings regarding association between religious beliefs and mental and psychological wellbeing was another motivation behind the present research. Furthermore, some new findings have been proved that the cross cultural perspective influence the link between religiosity and psychological well-being (Klanjsek, Vazsonyi, \& Trejos-Castillo, 2012; Nunez, Moral, \& Moreno, 2010). Therefore, recent study explores the effects of religiosity in terms of Islam on psychological wellbeing and distress of Pakistani peoples, which has specific eastern culture.

\section{Method}

\subsection{Objectives}

$>\quad$ To find out the relationship among religiosity, psychological distress, and mental well-being

$>\quad$ To investigate the gender differences in religiosity, psychological distress, and mental well-being.

\subsection{Hypotheses}

$>\quad$ There would be a significant negative relationship between religiosity and psychological distress.

$>\quad$ There would be a significant positive relationship between religiosity and mental wellbeing.

$>$ There would be a significant negative relationship between psychological distress and mental wellbeing.

$>\quad$ The level of religiosity would be higher among women as compared to men.

$>\quad$ The level of psychological distress would be higher among women as compared to men.

$>\quad$ The level of mental wellbeing would be higher among men as compared to women.

\subsection{Study Design}

For the current study, cross sectional survey design for was used. In cross sectional researches, concerned variables in a sample of subjects are considered once and the relationships among them are checked (Hopkins, 2008).

\subsection{Sample}

In the present study sample comprised of $(N=100)$ males and females which were selected through purposive sampling technique from district Mianwali, Chashma and university of Sargodha. Participants were distributed into two groups $(n=50)$ females and $(n=50)$ males. Minimum academic qualification of the participants was intermediate. Age range was $18-30(M=22, S D=1.4)$.

\subsection{Measures}

Centrality of Religiosity Scale (CRS; Huber \& Huber, 2012). Religiosity was measured with the help of the English language centrality of religiosity scale. It is 5-point Likert type scale ranging $(1=$ never, $2=$ rarely, $3=$ occasionally, $4=$ often, $5=$ very often $)$. The reliability range is $(\alpha=0.73$ to 0.83$)$.

The Kessler Psychological Distress Scale (K10; Kessler et al., 2002). The Kessler Psychological Distress Scale (K10) is a 10-item one dimensional scale specifically which is constructed to measure psychological distress in surveys. The K10 was constructed with item response theory models to enhance its accuracy and receptiveness in the clinical range of psychological distress, and this should be consistent with variety of age groups (Kessler et al., 2002). The scale assesses the level of anxious and depressive symptoms (e.g., nervousness, sadness, restlessness, hopelessness, worthlessness) over last one month. Each item is scaled from 0 (none of the 
time) to 4 (all of the time) and the total score is used to indicate level of psychological distress.

The Warwick-Edinburgh Mental Well-being Scale (WEMWBS; Tennant, Hiller, \& Platt, 2007). It is a 14 item scale for measuring mental wellbeing in varied populations. It comprised of positively worded items intended to evaluate the broader aspects of psychological wellbeing. The scale is scored by collecting the sum of responses to each item answered on a 1 to 5 Likert scale. The minimum scale score is 14 and the maximum is 70 . It is 5-point Likert type scale ( $1=$ never, 2 = rarely, $3=$ occasionally, $4=$ often, 5=very often). It showed good content validity. The computed Cronbach's alpha score of 0.89 for student sample and 0.91 for population sample. Test-retest reliability for a period of one week was high (0.83).

\subsection{Procedure}

Initially, heads of departments were contacted personally. They were informed about the topic of the study. After taking consent from them, participants were directly approached. Instructions about the scale and their answering booklets were given to them. They were asked to response on questionnaires of all variables according to their true emotions, feelings, and their religious attitude. All the participants were assured about the confidentiality and privacy of the information taken from them. At the end they were appreciated for their cooperation.

\section{Results}

\section{Table 3.1}

Frequencies and Percentages of the Demographic Characteristics of the Participants $(n=100)$

\begin{tabular}{|c|c|}
\hline Variables & Frequencies \& Percentage $(f, \%)$ \\
\hline \multicolumn{2}{|l|}{ Gender } \\
\hline Male & 50 \\
\hline Female & 50 \\
\hline \multicolumn{2}{|l|}{ Qualification } \\
\hline Intermediate & 25 \\
\hline Bachelors & 34 \\
\hline Masters & 39 \\
\hline Higher Education & 2 \\
\hline \multicolumn{2}{|c|}{ Family System } \\
\hline Nuclear & 56 \\
\hline Joint & 44 \\
\hline \multicolumn{2}{|l|}{ Birth Order } \\
\hline $1^{\text {st }}$ born & 24 \\
\hline Middle born & 29 \\
\hline Last born & 44 \\
\hline Only born & 3 \\
\hline \multicolumn{2}{|c|}{ Mother's Qualification } \\
\hline Metric & 71 \\
\hline Intermediate & 19 \\
\hline Bachelors & 4 \\
\hline Masters & 3 \\
\hline Higher Education & 3 \\
\hline \multicolumn{2}{|c|}{ Father's Qualification } \\
\hline Metric & 44 \\
\hline Intermediate & 14 \\
\hline Bachelors & 19 \\
\hline Masters & 22 \\
\hline Higher Education & 1 \\
\hline \multicolumn{2}{|c|}{ Monthly income } \\
\hline Less than 30,000 & 22 \\
\hline 30,000 to 70,000 & 57 \\
\hline More than 70,000 & 21 \\
\hline
\end{tabular}


Raza, H., Yousaf, A., \& Rasheed, R.

Table 3.1 describes frequencies and percentages of the demographic characteristics of the participants.

\section{Table 3.2}

Mean, SD, Internal Consistency and Correlation Matrix for Religiosity, Mental Wellbeing and Psychological

Distress $(n=100)$

\begin{tabular}{lllllll}
\hline & \multicolumn{1}{c}{ Variables } & $M$ & $S D$ & $\alpha$ & 2 & 3 \\
\cline { 2 - 7 } 1 & Religiosity & 61.50 & 6.77 & .76 & $0.29 * *$ & -.03 \\
2 & Mental well-being & 50.40 & 8.13 & .81 & -- & $-0.42 * *$ \\
3 & Psychological distress & 24.25 & 6.64 & .82 & -- & -- \\
\hline Note. ${ }^{* *} p<.01$ & & & &
\end{tabular}

Table 3.2 postulates mean standard deviations and internal consistency index (alpha coefficients) of all the variables analyzed in present study.

Table 3.3

Linear Regression Analysis of Perceived Religiosity for Mental Wellbeing $(n=100)$

\begin{tabular}{lccccc}
\hline \multicolumn{1}{c}{ Predictor Variable } & $B$ & $\beta$ & $S . E$ & $R^{2}$ & $F$ \\
\hline Religiosity & 0.36 & 0.29 & 0.12 & .09 & $9.36^{* * *}$ \\
\hline Note. ${ }^{* * *} p<.001$ & & & &
\end{tabular}

Table 3.3 explains that religiosity is significant positive predictor of mental wellbeing $\{F(2,98)=9.36, \beta$ $=.29, t=3.06, p<.001\}$ and it also demonstrates $9 \%$ variance in mental wellbeing that is contributed by religiosity $\left(R^{2}=.09\right)$.

Table 3.4

Linear Regression Analysis of Mental Wellbeing for Psychological Distress $(n=100)$

\begin{tabular}{lccccc}
\hline \multicolumn{1}{c}{ Predictor Variable } & $B$ & $\beta$ & $S . E$ & $R^{2}$ & $F$ \\
\hline Mental well being & -.51 & -.42 & .11 & 0.17 & $20.68^{* * *}$ \\
\hline Note. ${ }^{* * *} p<.001$ & & & &
\end{tabular}

Table 3.4 explains that Mental well-being is significant negative predictor of Psychological distress $\{F$ ( 2 , $98)=20.68, \beta=-.42, t=-4.54, p<.001\}$ and it also demonstrates $17 \%$ variance in mental wellbeing that is contributed by religiosity $\left(R^{2}=.17\right)$.

\section{Table 3.5}

Mean, Standard Deviation and t-test Analysis for Religiosity, Mental wellbeing and Psychological distress with gender $(n=100)$

\begin{tabular}{|c|c|c|c|c|c|c|c|c|c|}
\hline & $\begin{array}{l}\text { Male } \\
(n=50)\end{array}$ & & $\begin{array}{l}\text { Femal } \\
(n=50)\end{array}$ & & & & $95 \%$ & & Cohen's $d$ \\
\hline Variable & $M$ & $S D$ & $M$ & $S D$ & $t(98)$ & $p$ & $L L$ & $U L$ & \\
\hline Religiosity & 59.90 & 6.26 & 63.10 & 6.94 & -2.42 & $.01 * *$ & -5.82 & -.57 & 0.48 \\
\hline Mental well-being & 51.60 & 7.26 & 49.20 & 8.82 & 1.48 & .14 & -.80 & 5.60 & 0.29 \\
\hline Psychological & 21.78 & 4.95 & 26.72 & 7.22 & -3.98 & $.001 * * *$ & -7.40 & -2.47 & 0.79 \\
\hline
\end{tabular}

Note. $* * * p<.001, * * p<.01$

Table 3.5 indicates that there are significant mean differences in males and females on religiosity and psychological distress. It further indicates that the mean scores for the females significantly higher on religiosity $(M=63.10, S D=6.94)$ as compared to males $(M=59.90, S D=6.26)$. The mean score of psychological distress is significantly higher in females $(M=26.72, S D=7.22)$ as compared to males $(M=21.78, S D=4.95)$. 


\section{Discussion}

The present study examined the relationship among religiosity, mental wellbeing and psychological distress. As a first step, alpha reliability of scales was measured (see Table 3.2). The reliability of scale was satisfactory. Analysis of the data has revealed that there is no significant relationship between religiosity and psychological distress (see Table 3.2). These results in this area are being inconsistent with the research conducted on religiosity and psychological distress. A recent research explore the relationship between religiosity and mental wellbeing examines the impact of religious gathering, attendance and affiliation on psychological distress in community study of 720 adults, this study indicates that religious gathering, attendance and affiliation is not associated with psychological distress, religious affiliation and attendance does not overcome or buffer psychological distress (William's et al., 1991). Moreover, analysis of the data has revealed that there is significant positive relationship between religiosity and mental wellbeing (see Table 3.2). Several researches have concluded that in most of the cases indicators of religiosity are associated with aspects of psychological ill-health, and they are oppositely associated to mental health (Bergin, 1983). One of the phenomenon that is eager to explain this association is the buffering hypothesis religiosity may remove, overcome, or buffer the negative impact of stress on mental and physical health and wellbeing (Kendler, Gardner, \& Prescott, 1997).

Previous researches exploring the area of religiosity and mental well-being, majority of researches provide enough evidence to assist the positive association between religiosity and mental wellbeing. Lot of researches have been conducted in this context and found most important dimensions regarding religiosity is that religious peoples are mostly hopeful and positive about their future and this further leads toward mental wellbeing and psychological health (George, Ellison, \& Larson, 2002). Regression Test for prediction also (Table 3.3) explains that religiosity is significant positive predictor of mental wellbeing. Religiosity appeared as significant predictor of subjective well-being. It was found that religiosity (Predictor) emerged to influence significantly the youths subjective and mental well-being (Wani \& Khan, 2015).

With respect to third hypothesis, analysis of the data has revealed that there is highly significant negative relationship between psychological distress and mental wellbeing (see Table 3.2). Further analysis indicates that (Table 3.4) mental well-being is significant negative predictor of Psychological distress. Research in this area depicts that variables positively associated with psychological well-being were negatively related with psychological distress and vice versa (Winefield, Gill, Taylor, \& Pilkington, 2012).

Analysis of the study supported the forth hypothesis that the level of religiosity would be higher among women as compared to men (see table 3.5). Depicting various results from a large quantity of surveys, in 1975 they condensed the common intellect and wisdom at that time and concluded that on every standard woman are religious to a greater extent (Argyle \& Beit-Hallahmi, 1975). Based on cumulated findings of a wide range of studies, Walter and Davie (1998) generalized that male involve in religious gatherings and affiliations when they are publicly pleasing or even necessary, but in case when there is no social pressure they did not prefer religious practices. Thus occurring in the present, late modern religion, which is undoubtedly increasingly a matter of accepting not belonging, advocates the religious willingness of women (Davie 1990). In this context and same direction, Feltey and Poloma (1991) concluded, relied on a straight comparison of six measures of religiosity, that women have a higher level of close familiarity and intimacy with God than men in the same context. Whereas, accrediting lower level of religiosity among men in relation to their fear of familiarity and intimacy with God (De Vaus \& McAllister, 1987).

Furthermore, analysis revealed that level of psychological distress is higher among women than men and these results are consistent the previous researches as well as with fifth hypothesis (see Table 3.5). Researches on psychological distress have repeatedly reported differences among men and women as women experience higher level of distress than men (Almeida \& Kessler, 1998; Gove \& Tudor, 1973; McDonough \& Strohschein, 2003). Studies have inquired the gender-distress association from the point of view of cognitive-behavioural and gender role dimensions. According to the perspective of roles which are played by male and female, women are more 
Raza, H., Yousaf, A., \& Rasheed, R.

psychologically distressed than male because female roles expose them to more stressors in daily routine life (McDonough \& Walters, 2001). Research results from a 1990 U.S. sample of 1,282 women and 749 men indicates that on collective basis, women experience psychological distress about 30 percent more often than men. Research also provides evidence for gender-distress association that it is mediated by role-related stressors which are faced by both genders (Almeida \& Kessler, 1998).

The last hypothesis of the study was that the level of mental wellbeing would be higher among men as compared to women; results indicate non-significant gender differences. A research conducted by Roothman, Kristen, and wising (2003) showed that there is no significant difference between psychological wellbeing among men and women. Another research also claimed that there are no gender differences within the social dimension of psychological wellbeing (Bach, 2000; Crose, Nicholas, Gobble, \& Frank, 1992; Rout, 1999).

\section{Conclusion}

Results demonstrate that religiosity is significant positive predictor of mental wellbeing while non-significant relation was found with psychological distress. It also revealed that mental well-being is significant negative predictor of Psychological distress. Furthermore, the mean scores for the females significantly higher on religiosity and psychological distress as well.

\subsection{Limitations and Further Recommendations}

The present cross-sectional study has exposed very important findings; however it has also carried many concerns which should be considered in future. As sample was selected from limited locale so the findings cannot be generalized beyond the specific settings such that this research is particularly related to Islam, other religions may not be judged through this pattern. Further, there are also many sects in Islam so findings might be different for other sections. Therefore, it can effect on the generalizability of the study. In order to increase the external validity it should be replicated on large sample including different setting. Further, in the present study purposive sampling technique was used that reduces the chances of probability. So, it is suggested that in next studies random sampling technique should be practiced. Likewise, in future studies different age groups, cultures and participants including peoples with mental disorders should also be part of interest. In order to increase internal validity of the study many other factors like birth order, parental education and occupation, socioeconomic status and participant's academic record should be controlled.

\subsection{Implication of the Study}

Findings of present research would be helpful for social psychologists, educational psychologists, health psychologist and positive psychologist in many perspectives. Positive psychologist should incorporate purpose and meaning in people's life through religiosity so that the level of psychological distress can be minimized. Along with it, it will open new horizons of knowledge and awareness which would be fruitful in dealing with those families or peoples who are facing psychological distress and lack of mental wellbeing. Religiosity is a prime factor in wellbeing, hope, intellectual outgrowth and low rate of psychological problems by belief in God.

Acknowledgement: I would in particular sincerely thank to my mentor Prof. Ahmad Rafique Akhtar whose sincere prayers and support I always felt around me. I am also thankful to Anwar ul Hassan, Aamir Nadeem, Bilal Ahmed, and Aamir farooq for their unconditioned support and encouragement. It is because of them that I took on the challenge of higher education.

\section{References}

Abdel-Khalek, A. M. (2008). Religiosity, health, and well-being among Kuwaiti personnel. Psychological Reports, 102, 181-184. http://dx.doi.org/10.2466/pr0.102.1.181-184 
Religiosity in relation with psychological distress and mental wellbeing among Muslims

Abdel-Khalek, A. M. (2014). Religiosity, health and happiness: Significant relations in adolescents from Qatar. International Journal of Social Psychiatry, 60(7), 656-661. http://dx.doi.org/10.1177/0020764013511792

Aflakseir, A. (2012). Religiosity, personal meaning, and psychological well-being: A study among Muslim students in England. Pakistan Journal of Social and Clinical Psychology, 10(1), 27-31.

Almeida, D. M., \& Kessler, R. C. (1998). Everyday stressors and gender differences in daily distress. Journal of Personality and Social Psychology, 75(3), 670-680. http://dx.doi.org/10.1037/0022-3514.75.3.670

Argyle, M., \& Beit-Hallahmi, B. (1975). The social psychology of religion. London: Routledge \& Kegan Paul.

Bach, M. (2000). Stress, coping strategies, social support and the psychological and physical well-being of a group of academics. Unpublished Master's thesis, Potchefstroom University for Christian Higher Education, South Africa.

Bergin, A. E. (1983). Religiosity and psychological wellbeing: A critical re-evaluation and meta-analysis. Professional Psychology: Research and Practice, 14, 170-184. http://dx.doi.org/10.1037/0735-7028.14.2.170

Cornwall, M. (1989). The determinants of religious behavior: A theoretical model and empirical test. Social Forces, 68, 572-592. http://dx.doi.org/10.1093/sf/68.2.572

Crose, R., Nicholas, D. R., Gobble, D.C., \& Frank, B. (1992). Gender and wellness: A multidimensional systems model for counseling. Journal of Counseling \& Development, 71, 149-156. http://dx.doi.org/10.1002/j.1556-6676.1992.tb02190.x

Davie, G. (1990). Believing without belonging: Is this the future of religion in Britain? Social Compasa, 37(4), 455-469. http://dx.doi.org/10.1177/003776890037004004

De Vaus, D., \& McAllister, I. (1987). Gender differences in religion: A test of the structural location theory. American Sociological Review, 52, 472-481. http://dx.doi.org/10.2307/2095292

Deconchy, J. P. (1973). Boys and girls choices for a religious group. In L. B. Brown (Ed.), Psychology and religion (pp. 284-300). Hammondsworth: Penguin.

Denton, M., Prus, S., \& Walters, V. (2004). Gender differences in health: A Canadian study of the psychosocial, structural and behavioral determinants of health. Social Science \& Medicine, 58(12), 2585-2600. http://dx.doi.org/10.1016/j.socscimed.2003.09.008

Efficace, F., \& Marrone, R. (2002). Spiritual issues and quality of life assessment in cancer. Death Studies, 26, 743-756. http://dx.doi.org/10.1080/07481180290106526

Feltey, K., \& Poloma, M. (1991). From sex differences to gender role beliefs: Exploring effects on six dimensions of religiosity. Sex Roles, 25, 181-193. http://dx.doi.org/10.1007/BF00289853

Gartner, J., Larson, D. B., \& Allen, G. D. (1991). Religious commitment and mental health: A review of the empirical literature. Journal of Psychology and Theology, 19, 6-25.

George, L. K., Ellison, C. G., \& Larson, D. B. (2002). Explaining the relationships between religious involvement and health. Psychological Inquiry, 13, 190-200. http://dx.doi.org/10.1207/S15327965PLI1303_04

Gove, W. R., \& Tudor, J. E. (1973). Adult sex roles and mental illness. American Journal of Sociology, 78(4), 812-835. http://dx.doi.org/10.1086/225404

Hopkin, G. W. (2008). Research designs: Choosing and fine-tuning a design for your study. Retrieved from http://www.sportsci.org/2008/wghdesign.htm

Horwitz, A. V. (2007). Distinguishing distress from disorder as psychological outcomes of stressful social arrangements. Health, 11, 273-289. http://dx.doi.org/10.1177/1363459307077541

Huber, S., \& Huber, O. W. (2012). The centrality of religiosity scale (CRS). Religion, 3, 710-724. http://dx.doi.org/10.3390/rel3030710

Ismail, Z., \& Deshmukh, S. (2012). Religiosity and psychological well-being. International Journal of Business and Social Science, 3(11), 20-28.

Kendler, S. K., Gardner, O. C., \& Prescott, A. C. (1997). Religion, psychopathology, and substance use and abuse: A multimeasure, genetic-epidemiologic study. American Journal of Psychiatry, 154, 322-329. http://dx.doi.org/10.1176/ajp.154.3.322 
Raza, H., Yousaf, A., \& Rasheed, R.

Kessler, R. C., Andrews, G., Colpe, L. J., Hiripi, E., Mroczek, D. K., Normand, S., Walters, E. E., \& Zaslavsky, A. M. (2002). Short screening scales to monitor population prevalences and trends in non-specific psychological distress. Psychological Medicine, 32(6), 959-976. http://dx.doi.org/10.1017/S0033291702006074

Klanjsek, R., Vazonyi, A. T., \&Trejos, E. (2012). Religious orientation, low self-control and deviance: Muslim, catholic, eastern orthodox and Bible belt Christians. Journal of Adolescence, 35(3), 671-682. http://dx.doi.org/10.1016/j.adolescence.2011.09.003

Koenig, G. H. (2000). Religion and medicine I: Historical background and reasons for separation. International Journal of Psychiatry and Medicine, 30(4), 385-398. http://dx.doi.org/10.2190/2RWB-3AE1-M1E5-TVHK

Koenig, G. H. (2001). Religion and medicine II: Religion, mental health, and related behaviors. International Journal of Psychiatry in Medicine, 3, 97-109. http://dx.doi.org/10.2190/BK1B-18TR-X1NN-36GG

Kritchmann, M. L., \& Strous, R. D. (2011). Religiosity, anxiety, and depression among Israeli medical students. Israel Medical Association Journal, 13, 613-618.

Leondari, A., \& Gialamas, V. (2009). Religiosity and psychological well-being. International Journal of Psychology, 44(4), 241-248. http://dx.doi.org/10.1080/00207590701700529

Mc Donough, P., \& Strohschein, L. (2003). Age and the gender gap in distress. Women Health, 38(1), 1-20. http://dx.doi.org/10.1300/J013v38n01_01

McDonough, P., \& Walters, V. (2001). Gender and health: reassessing patterns and explanations. Social Science and Medicine, 52, 547-559. http://dx.doi.org/10.1016/S0277-9536(00)00159-3

Mirowsky, J., \& Catherine, E. R. (2002). Measurement for a Human Science. Journal of Health and Social Behavior, 43, 152-170. http://dx.doi.org/10.2307/3090194

Nunez, M., Moral, F., \& Moreno, M. P. (2010). Differential impact of religion on prejudice in Muslim and Christian samples. Escritos de Psicología, 3(4), 11-20.

Pargament, K I. (1997). The psychology of religion and coping. New York: Guilford Press

Ridner, S. H. (2004). Psychological distress: Concept analysis. Journal of Advanced Nursing, 45, 536-545. http://dx.doi.org/10.1046/j.1365-2648.2003.02938.x

Roothman, B., Kirsten, D., \& Wissing, M. (2003). Gender differences in aspects of psychological well-being. South African Journal of Psychology, 33(4), 212-218. http://dx.doi.org/10.1177/008124630303300403

Rosmarin, D. H., Pargament, K. I., \& Mahoney, A. (2008). The role of religiousness in anxiety, depression, and happiness in a Jewish community sample: A preliminary investigation. Mental Health, Religion \& Culture, 2, 1-17.

Rout, U. (1999). Gender differences in stress, satisfaction and mental well-being among general practitioners in England. Psychology, Health and Medicine, 4(4), 345-354. http://dx.doi.org/10.1080/135485099106081

Shafranske, E. P., \& Malony, H. N. (1990).Clinical psychologists, religious and spiritual orientations and their practice of psychotherapy. Psychotherapy, 27, 72-78. http://dx.doi.org/10.1037/0033-3204.27.1.72

Stark, R. (2002). Physiology and faith: Addressing the universal gender difference in religious commitment. Journal for the Scientific Study of Religion, 41, 495-507. http://dx.doi.org/10.1111/1468-5906.00133

Tennat, R., Hiller, L., \& Platt, S. (2007). The Warwick Edinburgh Mental Well-being Scale (WEMWBS): Development and UK validation. Health and Quality of Life Outcomes, 5(1), 5-63. http://dx.doi.org/10.1186/1477-7525-5-5

Wani, A. M., \& Khan, S. M. (2015). Subjective well-being and religiosity: A study of optimists and pessimists. The International Journal of Indian Psychology, 2(3), 104-114.

Winefield, R. H., Gill, K. T., Taylor, W. A., \& Pilkington, M. A. (2012). Psychological well-being and psychological distress: is it necessary to measure both? Psychology of Well-Being: Theory, Research and Practice, 2(3), 1-14.

World Health Organization. (2001). Mental health resources in the world. Initial results of Project Atlas. Geneva: World Health Organization. 